\title{
Editorial
}

\section{La anhedonia}

\author{
Héctor Perez-Rincón*
}

Evoquemos hoy este neologismo creado hace 118 años por el psicólogo y filósofo francés Théodule Armand Ribot (1839-1916) para calificar, como su nombre lo indica, la "incapacidad de experimentar placer". El término, cuya larga vida demuestra su utilidad, pues ha sobrevivido a otros neologismos propuestos a lo largo de la historia de la psiquiatría, muestra, por una parte, la necesidad que han tenido quienes la han construido de recurrir al griego y al latín con el fin de fabricar palabras y conceptos nuevos que ayuden a describir, si no a explicar, las complejas realidades clínicas que constituyen su quehacer cotidiano; pero, por la otra, es un buen ejemplo de que los términos que constituyen su estructura verbal y teórica no son sólo descripciones observables y medibles de signos y síntomas físicos semejantes a aquellos de los que se ocupan la neurología y las otras ramas de la medicina. La anhedonia, como otros hermosos vocablos de la medicina mental, evoca y se vincula con elementos de índole filosófica y literaria, que contribuyen a darle su peculiar y compleja condición de encrucijada entre lo biológico y lo cultural, entre lo subjetivo y lo histórico. Cierto, su estructura semántica la coloca junto a sus compañeras del diccionario con las que comparte esa "a" privativa: afasia, apraxia, alexia, acusia, acalculia, amusia, agrafia, ataxia, incluso anencefalia, pero a diferencia de sus parientes neurológicas posee una característica de constructo psicológico y teórico del que estas últimas carecen. Habría que colocarla entonces, más bien, junto a atimhormia, alexitimia, alexisomia, e incluso ataraxia.

\footnotetext{
* Universidad Nacional Autónoma de México (México, DF, Mx).
} 
Cuando Ribot recurrió al vocablo "hedoné", el placer, tenía muy claro el peso del concepto tanto en la mitología como en la filosofía griegas, cuya visión del hombre y del mundo han modelado la cultura occidental y las lenguas en ella surgidas. Personificada en una deidad femenina, Hedoné, hija de Eros y Psiqué, era el símbolo del placer en su vertiente de deseo sexual y de lujuria. Los latinos le llamaron, por ello, Voluptas. Sus contrapartes eran las daimon Algos: la pena y el dolor, tanto físico como emocional, Oisíz: la angustia y la tristeza, y Pentos: la aflicción y los lamentos, las tres, hijas de Eris: la discordia. Pero la anhedonia de Ribot no se limitaba, como podría pensarse por la especialización de la deidad que portaba el nombre de Hedoné, a la sola anafrodisia, a una anestesia del apetito genésico, sino que abarcaba una incapacidad para obtener satisfacciones placenteras de todos los componentes de aquello que, en una célebre y criticada Encíclica, Paulo VI llamó eufemísticamente: "el banquete de la vida". No es ocioso recordar aquí que las deidades que representaban la contraparte de Hedoné, como bien sabe la Psiquiatría, no dejaron de intentar suplantarla, como ocurre en la paradójica condición de la "algolagnia" - neologismo introducido en la primera década del siglo XX por un médico adicto a la parapsicología, el barón Albert von Schrenk-Notzing - para calificar a la erotización del dolor.

La introducción en el lenguaje psiquiátrico del vocablo creado por Ribot como sinónimo de insensibilidad al placer, o falta de placer, o déficit de la capacidad para experimentar placer, obligaba a los especialistas no sólo a diagnosticarla como un síntoma frecuente, incluso como un síndrome negativo, tanto en los estados esquizofrénicos como en los depresivos, sino también a considerarla, en una reflexión más amplia, en relación al hedonismo como filosofía del placer y al eudemonismo, la filosofía de la felicidad. No todos los psiquiatras, hay que confesarlo, pudieron aceptar el desafío. En efecto, ¿cuántos tuvieron acceso en su formación a las doctrinas de Epicuro de Samos o a las de Aristipo de Cirene, figuras tutelares de esa impostación filosófica? Con frecuencia se piensa que el epicurismo es una búsqueda desaforada de placeres, especialmente físicos, en tanto que en realidad se trata de una especie de matemática de los dolores y los placeres, una armonía del cuerpo y del espíritu en la que, tras una cuidadosa ascesis y entrenamiento personales se logra la "aponía": ausencia de dolores para el cuerpo y la "ataraxia": ausencia de trastornos para el alma. Resulta así inadecuado calificar como hedonista a nuestra época en la que predomina la búsqueda, a cualquier precio, del placer inmediato, y el consecuente temor patológico a todo tipo de sufrimiento.

La anhedonia debe, pues, contemplarse en relación a la ataraxia: ausencia de turbación, insensibilidad, indiferencia, propuesta como regla de vida por epicúreos, estoicos y escépticos. A diferencia de ésta, producto de un arduo trabajo personal, la anhedonia surge, ajena a la voluntad del paciente, obligándolo al empobrecimiento de sus capacidades de gozo en el mundo, de la que es claro ejemplo el personaje de "El lobo estepario" de Hermann Hesse.

Un psiquiatra que sí conocía bien las escuelas helenísticas, Jean Delay, el introductor del primer psicofármaco moderno, la clorpromazina, trajo a la ataraxia al 


\section{EDITORIAL}

terreno clínico al describir bajo ese nombre la indiferencia que el fármaco producía en los pacientes que la recibían respecto de los contenidos alucinatorios y delirantes que los embargaban, y llamó ataráxicos a los neurolépticos o tranquilizantes mayores.

De manera paralela al uso del término anhedonia, perfilada con el tiempo ya sea como un rasgo de personalidad o como un estado de apatía afectiva de pronóstico reservado en el espectro depresivo, en 1922, dos psiquiatras franceses, Maurice Dide y Paul Guiraud, crearon el neologismo de "atimhormia" (del griego: a-privativa, timos: corazón, sentimiento, afectividad, y hormé: impulso vital) para describir una pérdida o una reducción del deseo o del interés hacia las motivaciones que eran propias del paciente, una pérdida de impulso y de deseo para satisfacer gustos y preferencias, acompañada de un aplanamiento afectivo. El síndrome, que fue muy bien acogido por la semiología francesa, no se acompañaba de otros síntomas característicos de la depresión ni de otras anomalías de la función intelectual o cognitiva. Esta lesión global del vigor yoico se consideró patognomónica de la esquizofrenia, por lo que se podría decir que existe un cierto traslape con el neologismo de Ribot. Por supuesto que las escuelas anglófonas nunca adoptaron el de Dide y Guiraud, no obstante describir, útil y heurísticamente, en un solo vocablo, la condición esquizofrénica. En cierto modo corresponde a los llamados "Conative disorders".

Los tres vocablos se traslapan, a su vez, por algunas de sus peculiaridades fenomenológicas, con el más antiguo concepto de tedium vitae: hastío, aburrimiento, inapetencia para la acción y el gozo, presente en el estoico Séneca y en el epicúreo Lucrecio, síntoma melancólico o resultado del hartazgo tras una vida dedicada a la molicie, como en el poema de Oscar Wilde que lleva ese título.

El otro pariente neológico que hizo su irrupción en la psicopatología ochenta años después del de Ribot, y ciertamente relacionado con él, fue el de "alexitimia" introducido por Peter E. Sifneos. Esta "ausencia de palabras para describir las emociones" exhibe igualmente un cierto traslape con su predecesor. Se caracteriza por: 1. Dificultad para identificar y comunicar emociones; 2 . Dificultad para distinguir entre emociones y sensaciones corporales; 3 . Deterioro de la capacidad de simbolización, evidenciada por una pobreza de fantasías y otras actividades imaginativas; 4. Preferencia para enfocar acontecimientos externos más que experiencias internas. La dificultad para experimentar placer puede ir de la mano con la incapacidad para expresar en palabras estados afectivos. Sifneos ha sugerido que la anhedonia representa una disminución global e irreversible de la capacidad afectiva y que todos los pacientes alexitímicos presentan características anhedónicas. No obstante, no todos los anhedónicos sufren alexitimia.

En nuestros días, la anhedonia tiene nuevos avatares: el DSM-III (1980) lo consideraba como un criterio de melancolía necesario (pero no suficiente). El DSMIII R y el DSM-IV han suprimido la característica de "necesario", aunque sigue siendo un síntoma "determinante" de la depresión mayor. En esta última versión el término 
anhedonia se define como "una pérdida del interés o del placer" y se considera como un "síntoma negativo" (no un criterio) de la esquizofrenia. En tanto que el ICD-10, de la OMS, incluye para el constructo "depresión somática" una referencia a la pérdida de interés o a la capacidad para el placer.

Por lo que respecta a los estudios neuropsicobiológicos, se ha relacionado recientemente a la anhedonia con los modelos que intentan explicar la dependencia a sustancias, los síntomas de abstinencia y su búsqueda desesperada o craving, en función del metabolismo dopaminérgico. Hay muchos estudios que sitúan su origen en las neuronas de DA-A10, pues los neurofisiólogos han descrito que su lesión produce un estado de anhedonia muy intenso. Cabría preguntarse, sin embargo, si reducir a ese substratum el rico background fenomenológico, psicopatológico, filosófico y literario del concepto no conducirá a un empobrecimiento teórico, a pesar de que tal vez en un futuro se logre encontrar una molécula que, actuando en esos sitios, pueda ayudar a los pacientes a la conquista del placer, primum movens de toda la actividad humana.

Prefiero concluir con un relato clínico que es un interesante testimonio vivencial, psicohistórico y perteneciente a la medicina narrativa:

Abderrahman III, octavo emir de Córdoba y primero en usar el título de califa, que accedió al trono a los veintidós años y duró en él más de cincuenta, afectado de "enfermedad sagrada", se ocupó en anotar cuidadosamente y con toda precisión “el número exacto de días en que había sido feliz". Al acercarse su muerte, en el 961, escribió: "He reinado más de cincuenta años, en victoria o paz. Amado por mis súbditos, temido por mis enemigos y respetado por mis aliados. Riquezas y honores, poder y placeres, aguardaron mi llamada para acudir de inmediato. No existe terrena bendición que me haya sido esquiva. En esta situación he anotado diligentemente los días de pura y auténtica felicidad que he disfrutado: SUMAN CATORCE. Hombre, no cifres tus anhelos en el mundo terreno".

Si este príncipe no era un anhedónico, a fe mía que debe haber sido un señor muy exigente.

San Lorenzo Huipulco, junio 2013

\section{Héctor Pérez-Rincón}

Professor de Psicopatologia e História da Psiquiatria nos cursos de Pós-graduação em Psiquiatria, Universidade Nacional Autónoma de México (México, DF); Instituto Nacional de Psiquiatria Ramón de la Fuente Muñiz (México, DF).

Calzada México-Xochimilco 101. Colonia San Lorenzo Huipulco

Delegación Tlalpan, 14370 México, D. F. E.

e-mail: perezrh@imp.edu.mx 